\title{
CMAJ's century reflects a profession and a country
}

\author{
Charlotte Gray BA
}

$\mathrm{T}$

he first decade of the 20th century was frenetic, with manned flights and Model T cars in the United States and a naval armaments race in Europe. Medical and scientific knowledge was expanding at warp speed: Ivan Pavlov won the Nobel Prize for his research into digestion, Ernest Rutherford was exploring atomic structures and Paul Erhlich was developing an effective drug for syphilis.

And Canada? With a population of 5.3 million, the young country clung to British apron strings as it tottered toward sovereignty. Yet exhilaration swept this land too, and its growing professional class. Officers of the Canadian Medical Association, founded in Québec City, Quebec in the year of Confederation, 1867, shared the optimism. In 1911, the association took a bold step. To solidify its national and international ambitions, it established the monthly Canadian Medical Association Journal, an amalgamation of the Montréal Medical Journal and the Maritime Medical News. The first issue promised to be "a medium for the expression of all that is best in Canadian medicine." It was going to show the world that the country's small cadre of some 7500 universitytrained doctors deserved to be taken seriously. From the start, the founding editor, Dr. (later Sir) Andrew Macphail, Professor of the History of Medicine at McGill University in Montréal, set high standards for the journal and its contributors. He championed professional autonomy. "The free play of the profession is impeded by unconsidered legislation." And he wanted articles to be readable. "There is probably more bad writing in medical journals than in any other kind of periodical."

In the century that has passed since CMAJ's first issue (which consisted of 100 pages of dense print), the profession itself has grown in strength (to more than 83000 physicians) and credibility. The society around it has evolved from a largely rural population with European roots to a multicultural, multilingual, urban country with a population of 32 million and a gross domestic product that is the 11th largest in the world. But for 100 years, the same issues have preoccupied both the journal's 16 subsequent editors and the CMA's steadily growing

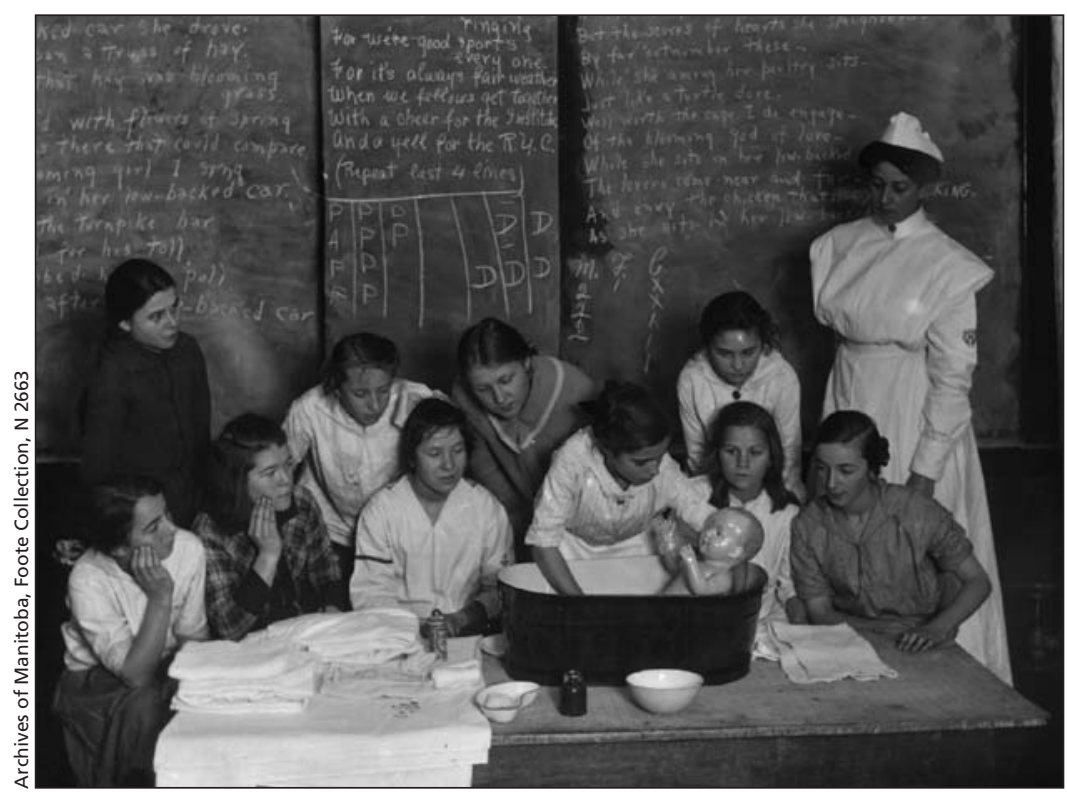

At the time CMAJ began publishing, infant mortality rates were soaring to over 20 per cent, prompting government agencies to introduce public health education programs. In this 1916 photo, a public health nurse in Winnipeg, Manitoba uses a doll to show young women how to bathe a baby.

membership: the profession's need for good science and a collective voice. CMAJ is a mirror of both our doctors and our country. It is also a periodical that has trodden a delicate line between its role as house organ and the journalistic impulse toward independence.

$C M A J$ was established at a propitious moment in medical history: 1911 was probably the first year, medical historian Michael Bliss reminds us, that "an ordinary person visiting a doctor is said to have been more likely to be helped than harmed." This was partly thanks to medical advances, such as x-rays, and partly because 1911 was also the year that there was finally a legal requirement for physicians to apply for a licence to practise. Popular 19thcentury nostrums like the widely advertised "Dr. Williams' Pink Pills for Pale People" began to lose their lustre.

In the journal's first decade, when almost all clinicians were generalists, public health issues quickly emerged as a priority. With life expectancy at only 52 years, and infant mortality rates of over 20 per cent, physicians faced a
This is the first in a series of articles marking CMAJ's 100th anniversary.

CMAJ 2011. DOI:10.1503 /cmaj.101799 
catalogue of communicable diseases - smallpox, polio, tuberculosis, cholera, syphilis and typhoid - for which they could offer few remedies. Antibiotics and sophisticated technologies lay far in the future.

Macphail was a forceful character and a careful reporter, whose articles had been published in the Montreal Gazette and the Chicago Times. He recognized that most of the prevalent diseases originated in contaminated water, poor nutrition, alcoholism and overcrowded slums. However, he left it to the CMA president to advocate public policy. In the journal's founding year, it was not the CMAJ's editor but the CMA's president who argued in the journal's pages that the association should lobby "municipalities and the state that

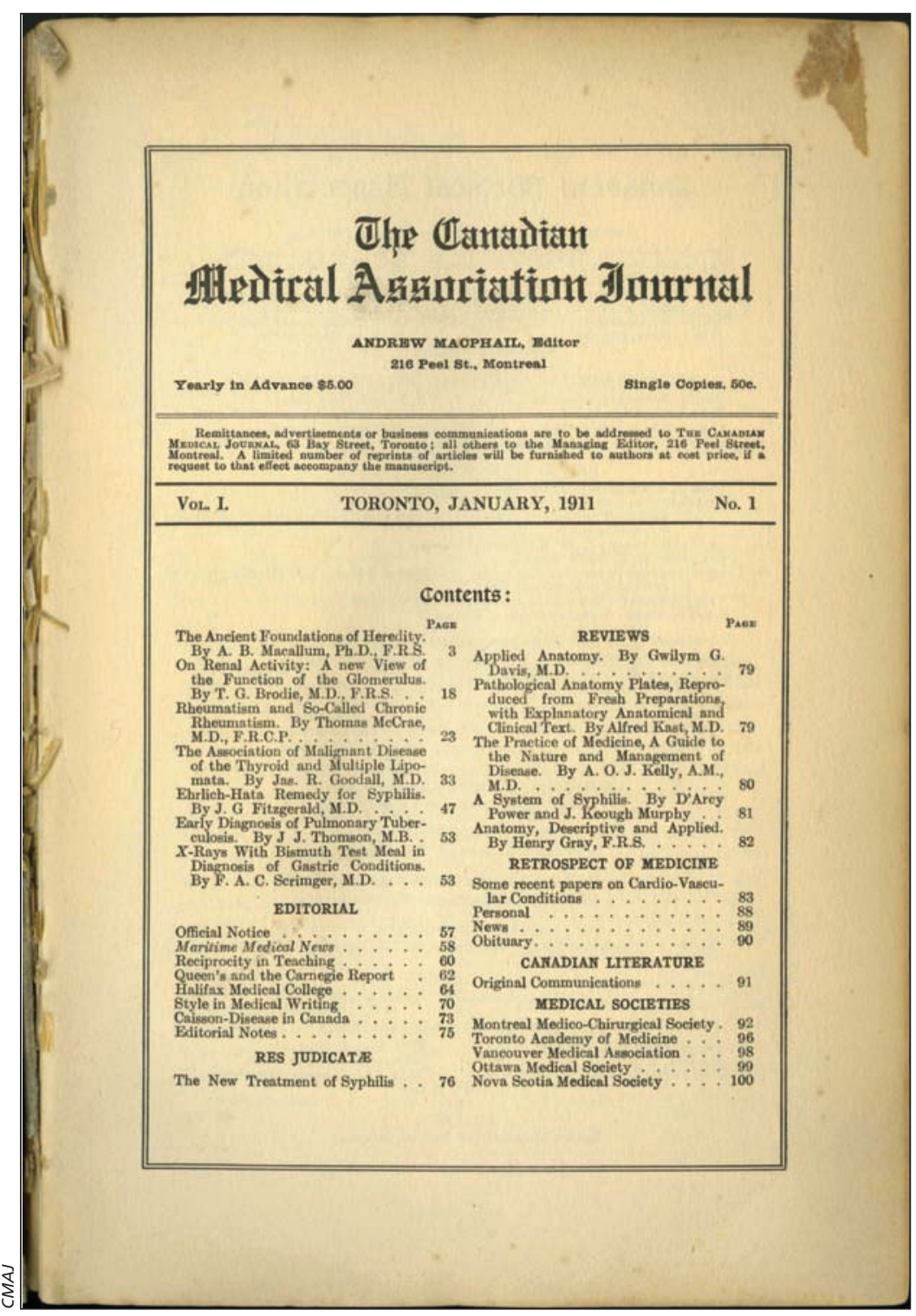

In the yellowing pages of CMAJ's first issue, tuberculosis was the "most important matter affecting the civilized world," and the possible benefits of a new treatment for syphilis, "606," were trumpeted. The complete inaugural issue is available on CMAJ's 100th page at www.cmaj.ca. money expended in providing so-called working classes with better houses, on wider and better lighted streets, would be more than recouped in a lessened expenditure in courts, prisons, asylums and hospitals." The CMAJ did, however, give an irresistible bully pulpit to some of its contributors who couldn't keep a whiff of moral righteousness out of their articles. In a 1911 piece entitled "Cocaine in Quebec," the writer minimized the dangers of the common stimulant with the offhand comment that only "a few degenerate creatures in the lower levels of city life employ it to alleviate their sense of misery."

Events across the Atlantic were about to unleash far more intense waves of misery. In September 1914, under the title "The War," Macphail informed readers that within the 20000 -strong 1st Canadian Division assembling at Valcartier, Quebec, was a medical corps of 50 physicians and 700 men. "It is a matter of congratulation that our profession is better prepared for the emergency than any other class in the community." Within a few weeks, he too had secured an overseas posting, despite being over 50 .

For the next four years, CMAJ displayed its determination to be a useful resource for readers by carrying regular articles about skin grafts, treatment of nephritis and amputations, as well as poignant obituaries of association members killed in the line of duty. One of the most moving appeared in March 1918. It was almost certainly Macphail himself, a close friend of John McCrae, who described how "Jack" was beloved of patients and students. He noted sadly, "His name will live in poetry. The help to recruiting and to Victory Loans (public funding of the war effort) brought by his In Flanders Fields was enormous." Another death, in 1919, was the occasion of a special memorial issue of the journal in January 1920. It honoured Sir William Osler, renowned as the father of modern medicine and universally acknowledged to be the most famous physician produced by Canada. Osler had also written a regular column, "Men and Books," for CMAJ, which boosted the journal's reputation and circulation.

Following the war, doctors still grappled helplessly with major health issues, with the influenza pandemic that had claimed 50 million lives around the world prompting a May 1920 article bemoaning the inadequacy of research on Bacillus influenzo. However, the journal soon began publishing and celebrating the rapid advances of modern medicine in the first half of the 20th century. In 1922, Banting and Best (and colleagues) wrote a "preliminary report" about their momentous discovery of insulin, for which they received the Nobel Prize a year later. Canadian readers first learned about the use of living sutures in 
surgery, the first successful grafts of blood vessels and radium treatment for cancer in the journal's columns. Dr. Wilder Penfield published on the physiology of the brain. Editors who filled Dr. Macphail's shoes continued his scientific rigour and his dry wit: in July 1937, a tongue-incheek "Ode to the Tonsils" was published. At the

\section{"There is probably more bad writing in medical journals than in any other kind of periodical."}

same time, moral judgements continued to colour medical practice. In July 1930, under the title "Sterilization for human betterment," one author urged wider use of sterilization to prevent births of "the weak, the degenerate and the generally unfit." He deplored the fact that, "at one time, we bred from the top; now [thanks to medical advances and charity] we breed from top and bottom, and, indeed, rather more from the bottom." The dangerous implications of the eugenics movement would soon become horribly evident in Nazi Germany.

As the bruising Depression took hold in the 1930s, doctors began to worry about unpaid bills, and their concerns showed up in the Medical Economics and Correspondence columns. Discussions about government-sponsored health insurance began, with tension simmering between those who favoured government schemes and those who shared Macphail's early resistance to "unconsidered legislation." In March 1935, Dr. J. C. McMillan was the first of many writers to explore in print ideas to resolve the situation. Under the title, "A Proposed Scheme of Health Insurance for Manitoba," he described how "the present depression has served to reveal many inherent weaknesses in our present system of supplying medical services." He deplored the move in Saskatchewan to a system of 107 "municipal doctors," salaried by the government, and instead calculated how a medical association might run its own insurance system, financed through provincial taxation. It was a harbinger not only of the great Canadian Medicare battle of the 1960s, but also of the future shift in focus for CMAJ.

But first events in Europe once again directed Canadian attention overseas. In October 1939, the lead editorial was titled simply, "War," and began ominously: "The die is cast. We are at war. It is needless to review the situation and ask, 'Why?" Soon pages were filled with articles about medical examinations of recruits, treatment of gunshot wounds to the brain and anticoncussion bandeaux. Within a year, there was a whole section called "The War." One-third of Canada's physicians, some 3800 , would eventually serve in the armed forces. CMAJ, still a drab monthly publication with columns of small print, was more concerned with clinical medicine on the battlefield than with the economics of health care services at home. In 1942, a special bulletin was prepared for physicians serving overseas. It had little impact, however: bundles of the publication were discovered at war's end, neatly packaged in the CMA's Toronto headquarters. They had never reached Europe.

The troops were barely out of uniform before the CMA, and provincial medical associations, started work on health insurance proposals. The Beveridge Report in Britain, which established the National Health Service, was fiercely debated in Canada - nowhere more fiercely than in CMAJ. However, as a January 1949 editorial pointed out, there were constitutional obstacles to such a universal system of health care on this side of the Atlantic. The federal government had already embarked on a system of provincial grants, but "we have yet to make our weight felt in the shaping of policy." It was not going to be easy for the national association to reach consensus on national needs, when the initiatives

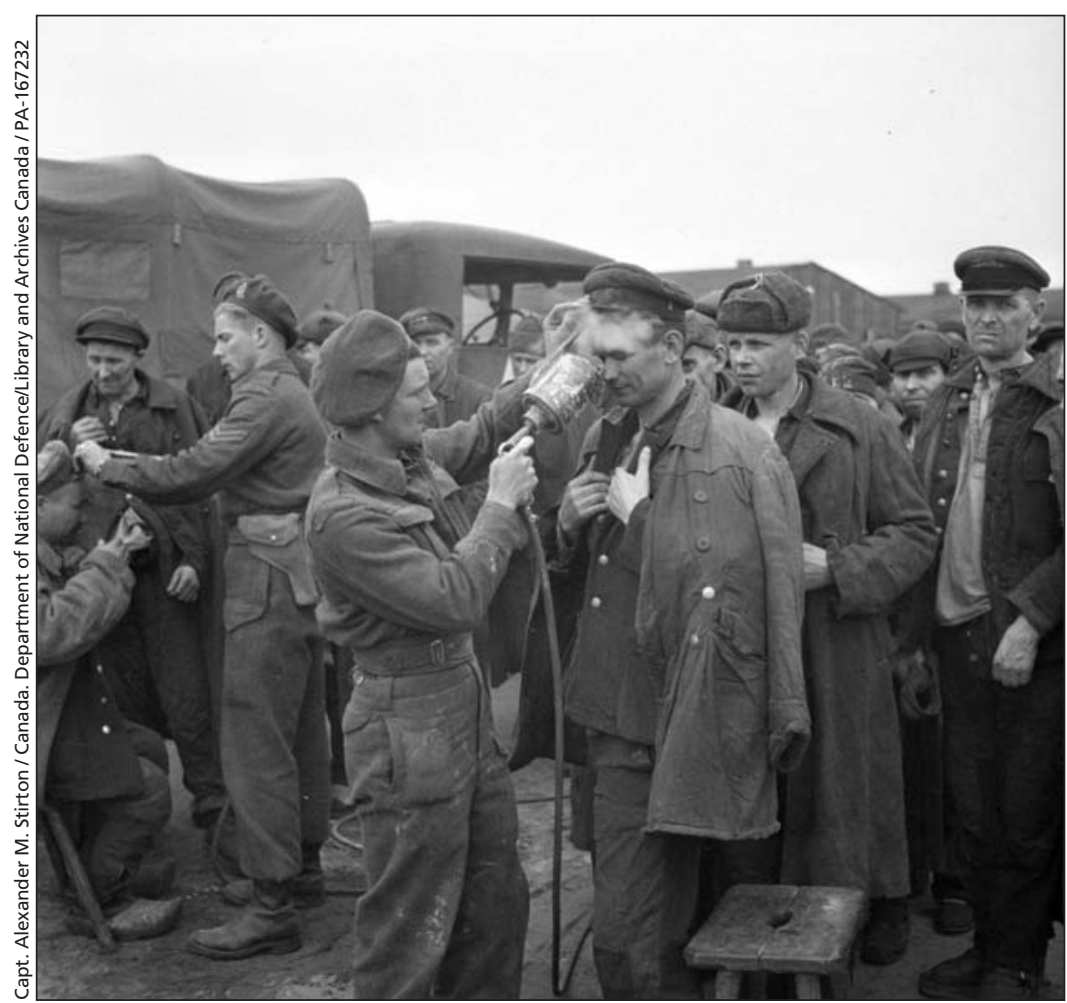

One-third of Canada's physicians, some 3800, served in World War II. In this April 14, 1945 image, personnel in a field hygiene section of the Royal Canadian Army Medical Corps, delouse liberated Russian prisoners-of-war in Friesoythe, Germany. 
were all taken at provincial level. CMAJ maintained a scrupulously balanced tone in its comments, while association officers watched medical clout shifting toward provincial associations.

From this point onward, the CMA was preoccupied by the politicization of health care, but its leverage within Ottawa relied on the credibility and muscle of its members rather than any formal relationship. CMAJ, still primarily a scientific publication, made sure that doctors were kept informed about political discussions. And all along, the journal's literary pretensions remained. The September 1954 issue featured a verse entitled, "My amoeba is unaware" by the famous Montréal lawyer and poet F.R. Scott, which included the line, "Truly a marvel of adaptation, equally at home in ponds or paunches, since the beginning of life."

In the second half of the 20th century, Canada

\section{In 1955, the journal began publishing twice a month, which meant more space for science and commerce.}

once again plunged into a period of dramatic change. Suburbs sprawled across farmlands; cranes hovered over new steel-and-cement schoolhouses; ordinary families could finally afford cars, holidays and an avalanche of laboursaving domestic appliances. Increased affluence showed up in CMAJ articles about several new drugs for psychiatric conditions, a new section devoted to medical films and concern about some innovations. A correspondent in February 1955 argued that there were far too many television programs with medical themes, pandering to "unwholesome seekers after vicarious thrills." What would the writer have made of today's orgy of medical dramas, such as House and Grey's Anatomy? In step with political concerns outside the profession, CMAJ began giving its title in French as well as English in 1959, and including abstracts and the occasional article in French.

Up until then, advertisements had been confined discreetly to the back of the book, but in 1955 the journal began publishing twice a month, which meant more space for both science and commerce: the number of pages occupied by pharmaceutical company advertisers continued to mushroom. In 1948, the association reported revenue from $C M A J$ of $\$ 88$ 552: by 1958, it had jumped to $\$ 399214$. Cresting the wave of pharmaceutical advertising, the journal went weekly in 1967 and immediately began losing money; 29 months later it lost its postal subsidy and reverted to twice monthly publication. Despite the ad boom, the majority of pages continued to be filled with scientific and medicosocial articles. Editorial staff worked hard to persuade toplevel Canadian scientific investigators and educators to write for $C M A J$, rather than for journals like The Lancet, The New England Journal of Medicine or the British Medical Journal.

Major changes were also afoot outside the journal. By the 1960s, it was evident that a national public health care system was going to be introduced into Canada, administered provincially and funded from both federal and provincial taxes. During most of the feverish debates, CMA leaders rather than CMAJ editors articulated physicians' positions. Significant comments on the 1962 Saskatchewan doctors' strike appeared in the presidential address of Dr. W.W. Wigle, published in the journal. In a direct echo of the founding editor's concerns, Wigle warned about "the dangers and ominous presence of political expediency." But from the sidelines, editors offered a different view. An unsigned editorial in August 1962 denounced the "demagogues" who indulged in "violent criticism, much of which is formless, blind and unreasoning" and which contributed to the "hate-the-doctor phenomenon."

The Medical Care Act finally passed in 1966, and with the advent of medicare, physician numbers and income grew over the next three decades. The CMA found itself navigating through difficult issues like abortion, drug abuse, contraception, confidentiality and genetic counselling. This was the Mad Men era in which advertising equated cigarettes with masculinity and independence, and a proposed ban on smoking in hospitals proved controversial. Individual doctors struggled with increasingly complex taxation and regulation. Through the 1970s, CMAJ, now located in the same building in Ottawa as the CMA, strove to stay ahead of doctors' concerns. The journal provided information on cutting-edge genetic research, retirement savings plans and the use of computers in the office. It became a much more attractive publication, with a modular design, full-colour covers and glossy paper.

But medical publication was now a crowded market. Should CMAJ continue to try to uphold Macphail's original dictum, "a medium for the expression of all that is best in Canadian medicine," or should it concede some ground to specialty journals and focus on supplying information and oversight articles for a wider general audience?

By the end of the 20th century, CMAJ had opted for the latter course. Peer-reviewed scientific material remained the centrepiece, but there was an expanded letters section and more emphasis on public health and articles useful for a general practitioner. Back numbers from these 
years read like comfortable national conversations between colleagues. Its seminal series on evidence-based medicine continues to be extensively cited. Successive editors strove to provide often off-beat and provocative material in a news and features section that might catch a busy doctor's attention. There were also forays into the new discipline of medical humanities, including narrative medicine articles and critiques of contemporary art works. A poem entitled "Oh, I was there, too (Swissair flight 111, Peggy's Cove, September 1998)," by Shane Neilson, a clinical clerk, which opened with the chilling line, "Among the things that startle / are a set of lungs / perfectly removed from a body," was published in August 1999. The spirit of Dr. John McRae continued to hover over the journal.

However, as $C M A J$ edged into less traditional areas and became more professional and sophisticated, its role as the CMA's house organ grew increasingly unstable. The tension built under Dr. John Hoey, who became editor in 1996 and liked to challenge readers - and the CMA - with editorials on controversial issues such as decriminalization of marijuana. In November 2005, matters came to a head over a draft news article about behind-the-counter access to emergency levonorgestrel. Citing concerns that readers might mistake the article for research, the CMA executive insisted that certain sections be deleted. The article was revised, and shortly after Hoey published an editorial objecting to "interference in editorial decisions." Within a few months, Hoey and a senior editor were dismissed, and several other editors resigned. CMAJ found itself the subject of unflattering media attention. Following on an external review headed by Montréal lawyer Dick Pound, the arm's-length relationship between journal and association was clarified, with a strengthened oversight committee.

Meanwhile, the Internet revolution was rocking the world of media globally. Under Hoey and Dr. Paul Hébert, who became the journal's 17 th editor in 2006 , the emphasis on online offerings increased, with the website becoming the "journal of record" in 2004. Today, far more material appears online at www.cmaj.ca than in the 18 print issues published annually. Despite the changing emphasis, Hébert remains loyal to the paper version. "Every time we do reader surveys, we hear that people like the print journal."

Although medicine, the profession and the country itself in 2011 would be unrecognizable to Sir Andrew Macphail, he would likely recognize the tone of scientific enquiry and professional civility that still characterizes $C M A J$. As the journal enters its second century, its editorial team has many of the same preoccupations as the

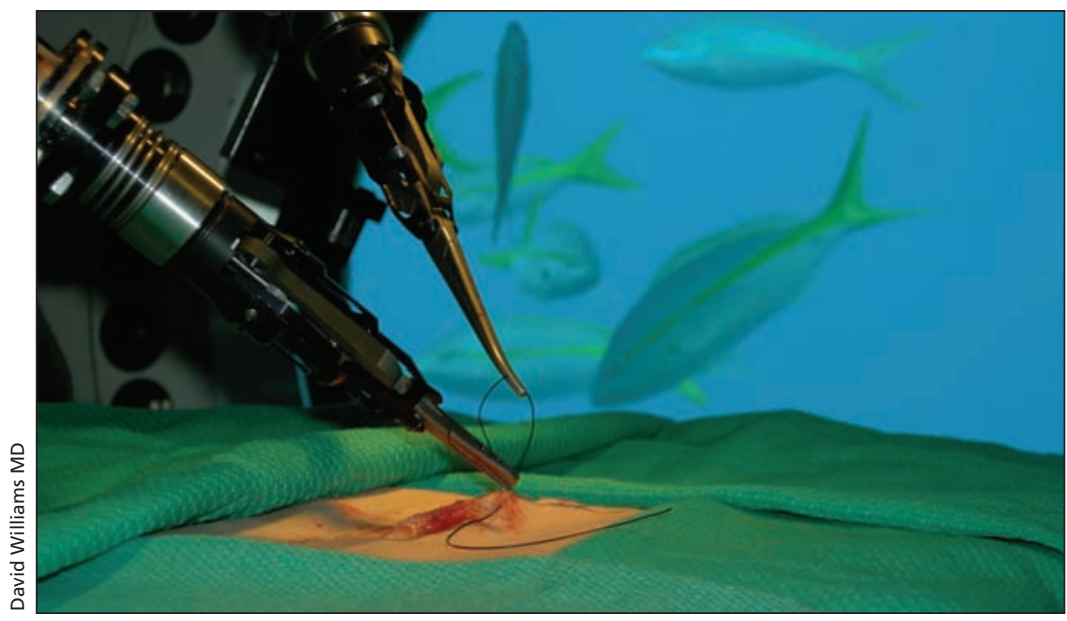

Today, high technology and evidence have transformed medicine. Medical researchers at the NASA Extreme Environment Mission Operation (NEEMO) are experimenting with robotic surgery underwater - conditions that mimic those in space.

founding editor, including a commitment to providing practical information to physicians.

But the journal is also hugely different with its international focus, contemporary, full-colour design, expanded news focus and influential editorials. Recently, the journal has deplored the Harper government's cancellation of the longform census, demanded early release of the H1N1 vaccine and urged caution in pursuing a radical new treatment of multiple sclerosis. Macphail would surely have applauded the crisp writing and passion embodied in these statements.

This first decade of the 21st century in Canada is the age of "there's-an-app-for-that" medicine. The average lifespan for Canadians is now 81 years and infant mortality is at 5.0 per 1000 live births. However, even though much has changed since January 1911, Macphail's original dictum that $C M A J$ be "a medium for the expression of all that is best in Canadian medicine" still stands, even if the same thing is said with fewer words in 2011: "Medical knowledge that matters."

\section{Charlotte Gray, an award-winning historian and} biographer, was a regular contributor to CMAJ for a decade. Her recently published eighth book is Gold Diggers, Striking It Rich in the Klondike. She is a member of the Order of Canada and a Fellow of the Royal Society of Canada.

\section{More CMAJ anniversary articles available at www.cmaj.ca}

- MacDermot HE. The fiftieth anniversary of the association journal. CMAJ 1961;84:1-5.

- Gray C. CMAJ: 75 years as the voice of the profession. CMAJ 1986: 135:1405-8.

- Wooltorton E. CMAJ, 90 years ago. CMAJ 2001;165:1631-4. 